Internships, professional experience years, consulting projects, case studies - benefits to graduate students:

- Develop specialized knowledge and industry insights which can lead to meaningful conversations with hiring managers

- Develop technical skills and behavioural strengths - Develop a portfolio of work that hiring managers can relate to

- Build relationships with professionals and peers - Explore career paths

- Showcase potential for future success

\title{
Getting hired in industry - life science graduate students use case studies to get noticed by employers
}

\author{
Adrian Yung ${ }^{1,2}$, Christina Wehrle ${ }^{2}$, Cricia Rinchon ${ }^{3}$, David Sealey ${ }^{2,4 \dagger}$ \\ ${ }^{1}$ Faculty of Arts and Science, University of Toronto; ${ }^{2}$ Science Career Impact Project; \\ ${ }^{3}$ Institute of Medical Science, University of Toronto; ${ }^{4}$ Department of Molecular Genetics, \\ University of Toronto; Toronto, Ontario, Canada.
}

\section{ABSTRACT}

Many career paths are possible after completing a life science graduate degree. How trainees pursuing careers in industry can compete effectively in the job market is of critical interest. While some trainees boost their marketability through internships, cooperative education programs, and/or consulting projects, these opportunities may be limited in number or availability, or challenging to arrange around research commitments. To explore career paths and build a portfolio of experience while in school, some trainees are taking an interesting approach: working in teams, with mentorship from industry professionals, they lead projects that simulate the kind of work they would be doing in their field of interest. After $\sim 130$ trainees have participated in the annual Industry Team Case Study program at the University of Toronto over four years, we interviewed four alumni to find out how their case studies helped them get noticed by employers and get hired.

\section{INTRODUCTION}

Gone are the days when the academic career track is seen as the only successful path after a life science graduate degree (Woolston 2018; Thon 2019). The University of Toronto 10,000 PhDs Project found that in 2016 approximately $40 \%$ of life science graduates from 2000 to 2015 were working in public, private or charitable sectors outside academia (Reithmeier et al. 2019). Similarly, the University of British Columbia PhD Career Outcomes Report found that in 2016 approximately $40 \%$ of health science graduates from 2005 to 2013 were working in private, public, or not-for-profit sectors (Porter et al. 2017). Given that most
Deposited at OSF Preprints:

November 11, 2019

Copyright: () Yung et al. 2019

Acknowledgements: The authors thank the many dedicated students and professionals who have volunteered their time and effort to develop and engage in the ITCS program. The ITCS program has been funded by Graduate and Life Science Education at the Faculty of Medicine, as well as a Community-Engaged Initiatives Grant from the Centre for Community Partnerships, University of Toronto.

Potential conflicts of interest: CW, CR and DS have been engaged in developing and delivering career development training and experiences through the Life Sciences Career Development Society and the Science Career Impact Project. No promotion of these programs to the exclusion of other similar programs should be construed. CW and DS are employed in the pharmaceutical industry; their employer was not involved in this work.

† Correspondence:

info@sciencecareerimpact.org 
life science graduate students spend the majority of their days focused on their research projects, how do they prepare themselves to be competitive in the nonacademic job market? While a recent survey revealed that many $\mathrm{PhD}$ trainees at the University of Toronto may not be doing enough (Her et al. 2018), there are ways to bridge the gap.

Employers look for a reason to believe that a candidate can be productive in the role and their organization. Life science graduate students develop valuable skills and experience for a variety of professions (Hankel 2019); however, some employers look for on-the-job professional experience even for entry-level positions, and may not be convinced.

To prepare themselves for the competitive job market, some students seek out action-learning experiences in which they can perform the day-to-day tasks of a professional and build their network. These experiences can take the form of internships (Talukdar et al. 2019), professional experience years, or consulting projects. Unfortunately, these options may be limited in number, may not be supported by all academic departments, or may be challenging to arrange around research or personal commitments.

To crack the experience problem and explore career paths while in school, some life science trainees at the University of Toronto are taking an interesting approach: on evenings and weekends they pursue extra-curricular case study projects that simulate the kind of work they would be doing on the job. Investing in such a project with no job title or compensation may seem unusual, but the hope is that building a portfolio of relatable experience and knowledge will lead to a paid opportunity - and career track - down the road.

The annual Industry Team Case Study (ITCS) program, developed by the Science Career Impact Project (a volunteer organization) and the Life Science Career Development Society (LSCDS; a student group at the University of Toronto), began in 2016. The program provides a framework for teams of graduate students and postdoctoral fellows to lead projects with mentorship from industry professionals (Freeman 2017). In a typical ITCS project, trainees work together to identify a business or policy challenge. They investigate the topic using publicly available information and, in some cases, interviews with industry and healthcare professionals. Then they formulate insights and develop a report, white paper, infographic, or presentation to present a solution or persuade a target audience to follow a strategy. Along the way, mentors provide feedback and guidance on the proposed topics, information sources, and quality of the work, and explain complex aspects of their field. At the end of the program, groups present their project and learnings to their peers and mentors.
To date, approximately 130 life science graduate students and postdoctoral fellows at the University of Toronto and 19 mentors have participated in the ITCS program. Case study topics have spanned various functional areas of the biotechnology/pharmaceutical sector including regulatory affairs, medical affairs, market access (reimbursement), product development, clinical trials, marketing, business development, and government policy. We interviewed four ITCS alumni to find out how their case studies impacted their path to employment.

\section{METHODS}

Interviews were conducted over email from June 7 to August 25, 2019. Responses were edited for length and clarity, and verified by the interviewees prior to publication.

\section{INTERVIEWS}

\section{Parco Chan, MSc (2018), Dept. of Pharmacology \& Toxicology, University of Toronto; Market Access Consultant, IQVIA Canada}

Why were you seeking a career in industry, and when did you decide to follow this path?

I first became interested in a career in industry when I learned about how drugs were developed in an undergraduate course. The complexity and scientific rigour of the process fascinated me. As I explored this career path by talking to industry folks and doing research, I was attracted by its dynamic environment and inspired by the mentors that I knew. Later in graduate school, I developed an interest in business strategy, so I sought to marry the two together - the science and the business - and went into market access.

\section{What inspired you to gain case study experience?}

I wanted to learn first-hand about the work of an industry professional to inform my career decisions. ITCS had everything I was looking for: an opportunity to engage with an industry mentor and work through a relevant case study, something that they likely do in their own role.

\section{What were your case studies about?}

My first case study was in regulatory affairs. We developed a clinical assessment package [request for priority review] for ribociclib for the treatment of breast cancer. As a clinical researcher, this was a great transition experience as I still got to work with clinical data, but in a different, more strategic manner.

My second case study was in market access. Our team developed a strategy to obtain reimbursement for tezacaftor/ivacaftor and ivacaftor - a breakthrough therapy for cystic fibrosis. It faced challenges to get 
reimbursement as it had a high price tag. It was a great case study to learn about market access dynamics and build a strong strategy around it.

What challenges did you overcome to complete your case studies?

A key challenge in both case studies was the steep learning curve in navigating each functional area. Each has its own ecosystem of terminology, stakeholders, and objectives that our team had to learn and become fluent with. Luckily, our mentors shared key resources to help with this.

Another key challenge was developing a strategic mindset. This is essential in the industry as one has to be proactive in anticipating and overcoming challenges. For instance, in my market access case study, we anticipated government hesitation in accepting our proposed price, so we looked into alternative reimbursement structures to distribute their risk.

What were the most valuable learnings from your case studies?

Go in with an open, curious mindset. In my first case study, I was still in my research mindset and wasn't able to understand new industry concepts because I was trying to fit them into my own paradigm. Over time, I listened more and tried to learn about key concepts in these fields in my own time. If you have questions, ask your mentor or ask them to point you to a resource. Understanding the why and the larger context is key to remembering the lessons you learn.

\section{"The case study caught my interviewer's attention when he looked at my resume. He asked me to lead him through my market access strategy."}

What role did your mentors play in the case studies? How did they guide the team in the right direction?

My mentors played a combination of a facilitation and leadership role. For instance, when my market access team was trying to choose a topic, he listened and chipped in when we proposed a topic that would not be feasible. When we were elucidating the public reimbursement pathway, he explained how health technology assessment in Canada works as it is a complex space.

What did you learn from your mentor both within and outside the case study that helped guide you towards your current job?

Within the case study, I learned technical knowledge of the field, which helped me in my subsequent interviews and even the job itself. What was more important were the casual discussions we had about career and otherwise during our meetings, which gave me insight and perspective on my career and target job that were valuable to me navigating my transition to industry. For instance, my mentor told me that your first job didn't have to be the dream job, but it can be a stepping stone to take you where you want to be. Moreover, the interactions within the case study made me more comfortable in approaching my mentor outside the case study for career discussions. I learned valuable insights like figuring out what the right type of job for you is, the process of applying for jobs, and what to consider after getting an offer.

How did you use your case studies in the job application process?

I mentioned my case studies in my resume as I felt like they demonstrated that I had been proactive in learning about a new field. The case study caught my interviewer's attention when he looked at my resume. He asked me to lead him through my market access strategy. He introduced some hypothetical barriers, so I had to adapt my strategy around it in response. I think that discussion demonstrated my awareness of the field as well as my fluency in it.

\section{Alex Sin, PhD (2017), Dept. of Cell \& Systems Biology, University of Toronto; Regulatory Affairs Associate, 3M Canada (via Talentcor)}

Why were you seeking a career in industry, and when did you decide to follow this path?

As I reached the second half of my graduate degree, I began to realize that despite my passion for science, the research lifestyle was not aligned with my career goals. Having my schedule dictated by experimental timepoints or the constant pressures of publish or perish in an academic setting was not attractive to me. At this point, I began to look into options in the science industry. This included reaching out to my connections and attending career talks offered by the Life Sciences Career Development Society (LSCDS) at U of T.

\section{What inspired you to gain case study experience?}

I heard about the ITCS from a mentor in the pharmaceutical industry. What inspired me to apply to the program was his personal success transitioning from lab research to the industry by showcasing to employers a portfolio demonstrating his capability to perform work beyond laboratory research. That spoke to me. In scientific research, we generate data to convince reviewers. The same principle applies here. We need to generate evidence to convince employers. How can you create non-lab experience during your graduate studies? A case study was the answer. 
What was your case study about?

We assumed the roles of regulatory affairs professionals for a consulting company to introduce a vaccine into Canada that has only been approved in the U.S. We picked an already approved vaccine because there would be a wealth of published information about it. Using this information, we assembled a briefing document that is typically used to notify Health Canada of an upcoming new drug submission.

What challenges did you overcome to complete your case study?

This case study exposed me to a realm that was drastically different from my graduate thesis work. Before this case study, I only had a general concept as to what regulatory affairs was about. By placing me in a simulated role of a regulatory affairs professional, this case study challenged me to learn over a condensed period of time how Acts and Regulations govern Canada, as well as the proceedings that take place between the industry and Health Canada. I had to adapt my research and critical thinking skills, accustomed to the field of fundamental cell biology, to the processes and language of how clinical trials are administered as well as how the data can be translated for use in dialogue with the government.

What were the most valuable learnings from your case study?

Through working as a team with two other graduate students, I learned to better communicate my thoughts and ideas as well as to actively listen to others. Most importantly, I learned to recognize individual strengths as well as my own personal weaknesses to best delegate tasks to fulfill our shared goals for the project.

What role did your mentor play in the case study? How did they guide the project?

Our mentor provided guidance that a new drug submission would be too large of a task for the duration of the case study, thus the creation of briefing document was simulated instead. Our mentor guided us in choosing a drug candidate that would not only have sufficient data for us to perform the work, but could have a realistic impact if the work were performed in a real life setting. With an applicable scenario, our mentor helped us put into perspective the role of regulatory affairs in the industry. She offered feedback and guidance to ensure we progressed towards our goals. Moreover, there was very little micromanagement which fostered our independence and teamwork. Finally, our mentor was always patient and open to answering our questions related to the case study as well as personal experiences in the role of a regulatory affairs professional.

How did you use your case study in the job application process?
I described my case study experiences in my cover letter and resume, and for every job application I have included a portfolio of my selected work which included the deliverable for this case study. When invited to interviews, I would bring a physical copy of the aforementioned portfolio, so that when asked to describe my experiences, I had the portfolio as a visual aid.

What comments or feedback did your hiring manager provide about your case study?

All the jobs I have applied to during my job search were in the scientific industry. As such, many of my competitors have similar academic backgrounds to mine. With my description of my experiences along with the presentation of my portfolio, hiring managers have appeared impressed by my demonstration of applied skills that are not limited to academic research. Some have expressed that they have never encountered any other applicants that make use of a portfolio to demonstrate evidence of experience.

\section{"Some [hiring managers] have expressed that they have never encountered any other applicants that made use of a portfolio to demonstrate evidence of experience."}

Tell us more about your portfolio. What was in it, and why do you believe it has given you a competitive advantage in job interviews?

My portfolio consisted of: 1 . Scientific communication piece I did for the MS Society. This was used to showcase my abilities to communicate complex scientific information to a lay audience. 2. Pre-New Drug Submission (NDS) briefing document from the ITCS. This was used to demonstrate my understanding of regulatory processes and my ability to compile information per the requirements of a government submission. 3. My first-authored cell biology publication. This was used to demonstrate to non-science interviewers (e.g., HR personnel) the end-result of a scientific research project. Because my paper consists of a large number of graphs, it serves as convincing evidence that I am capable of performing analytical work.

Based on your professional experience, how would you have prepared yourself differently during grad school?

I only truly began to explore the science industry in the last two years of my graduate studies. Though it took me until that time to learn what my strengths and weaknesses were and what kind of work lifestyle I wanted, I believe any student would benefit from attending career talks and networking as early as possible. It is easy to consider how many more people you would have been able to 
learn from and how many more industry projects you could have possibly done if you started earlier.

\section{Nathan Rutherford, MSc (2018), Dept. of Cell \& Systems Biology, University of Toronto; Regulatory Affairs Associate, Eurofins- Experchem}

Why were you seeking a career in industry, and when did you decide to follow this path?

I was originally interested in pursuing medicine. However, after my third year of undergrad, I felt that practicing medicine no longer matched my interests. I was way more interested in the parts of my courses that detailed more biotechnological applications of concepts (e.g., GMOs and transgenes, pharmaceuticals, regeneration, etc.). I decided to do an MSc in developmental and cell biology and hopefully work in the biotech industry afterwards.

During graduate school, I found that a lot of profs in my department and other graduate students knew a lot about their line of work and how to go through it, but had very similar stories and didn't know much about industry. Thus, to get this kind of information I had to actively network, seek mentorship programs, and learn about the pharmaceutical and biotech space so that I'd have a better idea of what areas of the industry I'd like to pursue.

I also wanted to find out what kinds of positions were suited to my strengths. I eventually settled upon regulatory affairs because I thought it meshed my longstanding interests in health science and public policy, and the job itself sounded interesting from talking to people I networked with. Doing the case study in regulatory affairs and having such a great experience played a big part in this.

\section{What inspired you to gain case study experience?}

I decided to do a case study in the second year of my MSc when I was ramping up the networking and extracurricular activities before I graduated. I had been told in my first year that $\mathrm{U}$ of $\mathrm{T}$ did not have a lot of career-related services and clubs but I found that when I looked for them this wasn't the case. I tried to be aware of programs hosted by the LSCDS and non-university groups such as the Graduate Management Consulting Association and Life Sciences Ontario. I also did mentorship programs with the LSCDS and Hart House.

I went to a lot of panels and workshops and various events on my own time to try and find out what I was missing. I decided that I needed some kind of hands-on volunteer-type experience and I was really intrigued when I found out about ITCS because I thought it would be an experience that would complement my MSc.

Also, I thought it would be a good testing ground for my ideas of what industry and specifically regulatory affairs would be like as a job and whether I would actually enjoy them or just liked the idea of industry.

What was your case study about?

I was in a team with three others and our mentors suggested doing something about cannabis regulatory affairs as the federal government had just released their cannabis regulations in October 2018.

We tried to figure out if there were any gaps in the regulations. As it turned out, we realized that the regulations released in October 2018 were for a limited selection of cannabis products such as dried cannabis, and that other products derived from cannabis such as edibles were not included in the regulations. Instead, the government was going to release a second wave of regulations that addressed cannabis edibles by October 2019. We decided to address this with our case study and see if we could determine some regulations for edibles that would be made. To do this, we compared the regulatory landscape for cannabis edibles in four US states (Washington, Colorado, California, Alaska) and tried to see how their systems would fit into Canada's. We wrote a white paper and made infographics that could be used to inform the public about cannabis edibles.

When the government released their proposed edibles regulation in November 2018 we saw that we had actually been correct about a few things. For example, the THC limit per serving was what we thought it would be and we were also pretty close on a variety of packaging and labelling requirements.

What challenges did you overcome to complete your case study?

Reading the government regulations. They are very circular, constantly referencing lines in other acts and regulations as well as earlier or later within the same document. The result is that you can't read them from start to finish as you would a novel but instead read them and keep jumping around to different spots and different documents.

What were the most valuable learnings from your case study?

I learned how to read regulations. I had a lot of fun. I actually enjoyed reading all the regulations and looking at the different jurisdictions and trying to build our own set focused on a particular topic. It was also a glimpse into "how the sausage is made" for public policy, and it helped show me that I was moving in the right direction for a career best suited to me. Additionally, my mentors introduced me to the Seneca College post-grad program, which I am currently attending. I probably wouldn't have considered the post-grad if I hadn't done ITCS.

What role did your mentors play in the case study? How did they guide the team? 
My mentors were very helpful in guiding the team. They also suggested getting a feel for the regulations first and then determining what was missing. We decided to focus on the edibles as no regulations had been made on them at that point. They also showed us how to read the regulations. We met with them every two weeks in person and shared what we had found out and where we thought we would go next. They suggested looking into related areas and seeing how they fit back into our work. We wrote a white paper outlining our findings as a deliverable and I believe it was our mentors who suggested that format. They helped with editing this document and suggested areas we should add or expand upon.

How did you use your case study in the job application process?

Admissions to the Pharmaceutical Regulatory Affairs post-grad at Seneca are competitive and you're required to write an English test and complete a series of written questions. I featured the case study heavily in the written questions: as an experience working in teams, talking about strengths, and about how having the experience showed that I was really passionate about regulatory affairs and was legitimately interested in the program. Five days after I wrote the test/essays I got on the waitlist, and two days after that I got into the January start. I wasn't expecting to get that news then or that fast and I was pleasantly surprised!

I talked about the case study a lot during the job application process for the work-term placement. I included it in my cover letter and the hiring managers were very interested in it during interviews. This was also the case after I completed my MSc but before I started at Seneca. I had applied to a number of jobs before applying to the Seneca program and I always tried to showcase it in cover letters and interviews. It provided an excellent story for the "why do you want to do this" questions.

When I first walked into my interviewer's office I noticed that they had a Chemistry of Cannabis poster behind their desk so I realized I should bring up the case study as soon as possible. I think I brought it up when she asked me "why regulatory affairs?" or a similar question.

In the interview I described what we did as part of the case study and what we found out about cannabis edibles and some estimates we came up with about what future regulations would look like. I talked about some expected regulations that we were right about, like the THC limits of $10 \mathrm{mg}$ for cannabis edibles.

What comments or feedback did your hiring manager give about your case study?

The manager was very interested in the case study. Basically, my whole interview was about it and what I knew and thoughts about the cannabis industry as well as some stuff on regulatory affairs I learned in my first semester of post-grad. In other interviews, people also asked about the white paper and what we did with it. Some suggested that I write an op-ed.

How has your ITCS experience prepared you for the Seneca Post-Graduate experience? How does your level of preparation compare to that of your peers?

My case study experience was really good prep for my post-grad. A lot of my peers entered the post-grad after their undergraduate programs. From the case study and networking I had a fairly good idea of what Regulatory Affairs was. Doing the case study provided me with a good story explaining the reasons I was interested in regulatory affairs, which I used in the admissions process and in cover letters and interviews when I was applying for the co-op/placement. I do not think that most of my peers had an actual hands-on experience specifically in regulatory affairs before they entered the post-grad.

\section{"The manager was very interested in the case study. Basically, my whole interview was about it and what I knew ..."}

Reflecting on your graduate experience, what advice would you give your younger self to prepare for a career in industry?

Networking. If you want to go into industry, talk to people who are outside the lab/academia environment. I found that lab/academia people seem to lack advice about industry jobs unless they had a grad student who already went that route. Talk to people in industry, in government, in entrepreneurship. Go to the career panels and talk to interesting people on the panels. Invite these people for coffee. Go on LinkedIn and invite interesting people for coffee. Be up front about how you want to ask them about how they started their career. I found that these people were usually very helpful and happy to meet. I aimed to do a coffee chat every two weeks during my last year of grad school.

Talking to many people accomplishes two things you may not think about. Firstly, it increases your chances of being introduced to a cool program or experience or piece of wisdom you hadn't thought about before. Secondly, most of the people have great advice that can be helpful for you, even if it allows you to recognize a trend and adjust your own path accordingly; but some people are going to have advice that may have worked for them but is undesirable for you.

Case Study. Try and do a case study or get hands on volunteer experience that will complement your research experience. Make sure it's something you find 
interesting and you'll be able to talk passionately about it. Don't do it just to do it. I can draw a pretty clear line from doing a case study to what I do today.

Grad School. Don't overextend yourself, graduate school is the priority. I am very proud of the research I did, the thesis I wrote, and my paper. In addition, keep track of all the stuff you do including the non-experiment stuff. The TA-ing, oral presentations, posters, defenses, report writing, paper critiquing, data entry, marking, answering questions, etc. All required excellent transferable skills that you can tell people about.

Relax. And keep planning ahead.

\section{Tracy In, PhD (2018), Dept. of Immunology, University of Toronto; Medical Science Liaison, Novartis}

Why were you seeking a career in industry, and when did you decide to follow this path?

Right from the beginning, I knew I wanted a career in industry rather than academia. Even though I loved academic research, I've always been most excited by the interface of science and business. Translating novel findings generated by research into something impactful is what gets me going. I developed further fascination for the complex and competitive pharmaceutical landscape throughout my graduate studies, as I became more familiar with the industry through coursework, information sessions, networking and case studies.

What inspired you to gain case study experience?

Two reasons. First, I wanted to gain hands-on experience on what industry professionals do on a day-today basis. Second, I wanted a platform to showcase that I possess transferable skills that would make me an ideal candidate for an industry position.

\section{"All my hiring managers (for my internship and current job) were intrigued and impressed with my portfolio of case studies."}

\section{What were your case studies about?}

My first case study, which I did independently with the guidance of a mentor in the pharmaceutical industry, was about evaluating the clinical evidence of the safety and efficacy of an anti-IL-12/23 antibody versus an anti-IL17 antibody in the treatment of moderate-to-severe psoriasis. This was very close to my heart as my $\mathrm{PhD}$ project looked at IL-17-producing immune cells.

My second case study, which I did as a part of the ITCS program under the mentorship of a regulatory affairs professional, was compiling a pre-New Drug
Submission briefing document and product monograph for a novel oral vaccine. I did another case study looking at the treatment landscape for metastatic renal cell carcinoma in Canada, and a series of short case studies to understand the Health Canada regulatory approval process.

What challenges did you overcome to complete your case studies?

Time management was the most challenging piece, as I was juggling lab work, manuscript writing, volunteer work, job search and case studies at the same time.

What were the most valuable learnings from your case studies?

Learning the online tools that industry professionals use on a daily basis was very valuable. I use some of those tools on a daily basis in my work today. At the same time, realizing that the skills we gain in grad school are truly transferable and relevant was an eye-opener. As $\mathrm{PhD}$ students, we are trained (for many years) to ask relevant questions, seek relevant sources, problem solve, develop a solution-oriented mindset, grasp complex data quickly, critically assess data, and communicate effectively. Through the case studies, I experienced firsthand how I could apply such skills in the context of the pharmaceutical industry.

What advice would you give a student who is starting a case study?

Pick a topic that excites you. A case study project is a big commitment that will take your time away from the lab and other responsibilities you may have. You will naturally put in more time and effort if you are having fun, which will translate into a superior output.

What role did your mentors play in your case studies? How did they guide you and your team in the right direction?

One of my mentors in the pharmaceutical industry was the innovator behind the ITCS initiative. With his expertise and knowledge of the ins and outs of the pharma industry, he assessed the validity and relevance of my research questions, advised on the appropriateness of information, provided feedback on the presentation format and on the quality and completeness of the deliverable. He also provided guidance on publicly available resources and tools.

How did you use your case studies in the job application process?

I packaged my case studies into a portfolio and presented them to the hiring managers I interviewed with. I also listed them under the Education section on my resume, as I felt it was important to highlight that I took the initiative to take this extra step.

I can say with certainty that all my hiring managers 
(for my internship and current job) were intrigued and impressed with my portfolio of case studies. One common question I was asked was whether or not I did the case studies as part of my thesis, which I did not. This was a learning moment for me - that the 'why' and 'how' I did the case study was as important (or even more important) as the product of the case study itself. Hiring managers want to see that you are able to take initiative, seek appropriate resources, and build professional rapport with your peers (team members) and mentors to produce quality work.

What did you learn from your mentors both within and outside the case study that helped guide you towards medical affairs?

My decision to pursue a career in medical affairs specifically was not directly influenced by my case study mentors. However, from the case study experience, I learned and came to truly realize that the soft skills we gain from our $\mathrm{PhD}$ study are transferable across many different industries and sectors, which gave me the confidence to seek opportunities in medical affairs.

Based on your professional experience, what advice would you give your younger self during grad school to help prepare for your career?

Seek out your own development opportunities and don't sell yourself short.

\section{"Hiring managers want to see that you are able to take initiative, seek appropriate resources, and build professional rapport with your peers (team members) and mentors to produce quality work."}

\section{DISCUSSION}

Graduate school may be the ideal internship for becoming a professor, but trainees who want to explore non-academic career paths can benefit from adding a portfolio-building experience that employers outside academia can relate to. Our interviewees stretched themselves during their $\mathrm{MSc}$ and $\mathrm{PhD}$ programs to complete extra-curricular case studies that helped them clarify their target roles, get noticed by employers, and get hired.

The annual Industry Team Case Study program has been running at the University of Toronto for 4 years with a focus on life sciences and the biopharmaceutical sector. Conceivably, the model can be applied at any institution, and focused on any sector or discipline. Even without an organized program, any individual or team can start a case study focused on their target career.

Based on our interviewees' responses as well as our experience running the ITCS program, we identified a number of benefits that trainees may gain from case study experience.

Self-discovery

Without experience outside the lab, trainees who aspire to a career in industry may not be fully aware of the types of roles they are well suited for and may enjoy. Playing the part of an industry professional can help trainees to identify the technical skills and behavioural strengths they have that may help them in various roles, and to validate or clarify their desired career path.

\section{Specialized knowledge}

Each discipline has its own language, tools, practices, stakeholders and, in some cases, rules and regulations. In addition, organizations have departmental structures that may not be apparent to outside observers. By immersing themselves in projects and engaging with mentors, trainees absorb and apply this specialized knowledge which, in turn, can enable meaningful conversations with hiring managers, and productivity on the job.

\section{Industry trends and insights}

When investigating a hot topic, trainees learn about issues of concern to multiple stakeholders including customers, regulators, payers, and employees. Trainees uncover trends in, and develop insights about the field, the therapeutic and competitive landscape, and novel technologies.

\section{Networking}

Engaging with mentors and peers over the course of a case study helps to establish a community of support that can be called upon to discuss opportunities, challenges, and trends.

\section{Marketing yourself effectively}

A basic job application typically includes a cover letter and resume, followed by an interview for selected candidates. Adding a concise portfolio of work including a case study can provide evidence of skills, knowledge and experience that employers can relate to. Also, telling compelling stories about a case study in the resume and interview - why the topic is important, actions taken to investigate and report on it, and the impact/result of the effort - can help to showcase potential for future

Including a case study project in a job application can provide evidence of skills, knowledge and experience that employers can relate to. Telling compelling stories about the study project in the resume and interview can help to showcase potential for future success. 
success.

Experienced mentors can provide valuable guidance for case studies, especially at earlier stages of a trainee's development. Our interviewees offered advice for finding a mentor outside an organized program. Parco said, "Talk about why you want to do a case study, what you hope to learn, and what type of support you want from your mentor. Keep in mind that some people may not have the time to commit to this, so you might have to ask a few people. Hopefully, with an existing rapport, they will agree to work with you." Alex had the following advice: "Learn as much as you can about your mentor's expertise, then create several potential case study concepts. Suggest the possibility of mentoring a case study project during an informational interview. Outline what you aim to achieve from this relationship."

Each of us is in the driver's seat of our career. It is up to us to define the path we want to follow and develop the skills and experience we need to go in that direction (Drucker 1999). As an alternative or companion to an internship, pursuing a mentored case study before we have a job can help to acquire marketable skills, knowledge, and experience.

\section{REFERENCES}

Drucker, P.F. (1999). Managing oneself. Harvard Business Review, 77(2), 64-74.

Freeman, M. (2017, September 1). How case studies can help to smooth the academy-to-industry transition. University Affairs. Retrieved from https://www.universityaffairs.ca/ career-advice/career-advice-article/case-studies-can-helpsmooth-academy-industry-transition/.

Her, S., Jacob, M.D., Wang, S., Xu, S., \& Sealey, D.C. (2018). Non-academic employability of life science PhDs: the importance of training beyond the bench. bioRxiv. doi: $10.1101 / 485268$.

Hankel, I. (2019). Why earning a $\mathrm{PhD}$ is an advantage in today's industry job market. Nature. doi: 10.1038/d41586019-00097-x.

Porter, S. et al. (2017). UBC PhD Career Outcomes. UBC Graduate \& Postdoctoral Studies. Retrieved from https:// outcomes.grad.ubc.ca/, http://outcomes.grad.ubc.ca/docs/ UBC_PhD_Career_Outcomes_April2017.pdf.

Reithmeier, R., O’Leary, L., Zhu, X., Dales, C., Abdulkarim, A., Aquil, A., et al. (2019). The 10,000 PhDs project at the University of Toronto: Using employment outcome data to inform graduate education. Plos One, 14(1). Retrieved from https://www.sgs.utoronto.ca/about/10000-phds-projectoverview/10kphds-dashboard/.

Talukdar, M., Nadeau, V., Balo, A., Cemma, M., \& Lee, N. (2019, March 29). An internship during your $\mathrm{PhD}$ can be vital to your career development. University Affairs. Retrieved from https:/www.universityaffairs.ca/careeradvice/graduate-matters/an-internship-during-your-phd-canbe-vital-to-your-career-development/.

Thon, J. (2019, August 16). You are not a failure for wanting to leave academia. University Affairs. Retrieved from https:// www.universityaffairs.ca/opinion/the-black-hole/you-are-nota-failure-for-wanting-to-leave-academia/.

Woolston, C. (2018). Science PhDs lead to enjoyable jobs. Nature, 555(7695), 277. 